\title{
Study on Course Practice Teaching Based on Expectation Theory-Taking Job Analysis Course for Example
}

\author{
Fang Cheng \\ School of Business, Anyang Normal University, Anyang, China \\ Email: chengf_tina@163.com
}

How to cite this paper: Cheng, F. (2018). Study on Course Practice Teaching Based on Expectation Theory-Taking Job Analysis Course for Example. Creative Education, 9, 2811-2818.

https://doi.org/10.4236/ce.2018.916211

Received: December 3, 2018

Accepted: December 16, 2018

Published: December 20, 2018

Copyright $\odot 2018$ by author and Scientific Research Publishing Inc. This work is licensed under the Creative Commons Attribution International License (CC BY 4.0).

http://creativecommons.org/licenses/by/4.0/

\begin{abstract}
Job analysis is one of the important basic courses of human resource management major. In order to improve students' application ability training, job analysis has set up course practice. In order to stimulate students to participate in the job analysis curriculum practice, the expectation theory is introduced into the curriculum practice design, the model of the job analysis curriculum practice design based on the expectation theory is established, and the concrete scheme of the job analysis curriculum practice is proposed.
\end{abstract}

\section{Keywords}

Expectation Theory, Job Analysis, Course Practice

\section{Introduction}

It is one of that key improvement of education in China to improve the practical teaching level, train the practical ability of the student and meet the need of enterprise application talents. Job analysis is the foundation of professional courses of human resource management. It is one of the courses with high technical content and strong practical operation in human resource management. However, at present, the practice of the course "job analysis" of human resource management major is mostly completed in the human resource training room or practice base, which lacks applicability and systematicness and is difficult to stimulate students' enthusiasm for learning. How to design a curriculum practice system to stimulate students' enthusiasm for learning is worthy of attention. Therefore, this paper introduces the theory of expectation into the practical teaching design of "job analysis", and systematically designs the practical teach- 
ing of "job analysis", in order to improve students' learning enthusiasm and guide students to obtain high-quality employment.

Job analysis is a very important basic course in the management of resources management, which is the basis of the recruitment and retort, training and development, performance management, and compensation management, but there is no mention of the job analysis in the six modules of human resources management. At present, Chinese enterprises, especially small and medium-sized enterprises, mainly focus on recruitment, performance management, salary management and other aspects of human resource management. Job analysis has not received due attention, and even considered it optional. At the same time, traditional practical teaching is usually completed in the laboratory or training room, mainly in the simulation of practice; the practice process management is loose; the practice result is limited to the student ability cultivation. From the perspective of future career development and capacity cultivation, the traditional "job analysis" practical teaching is difficult to attract students to pay attention to this course. On the other hand, job analysis course learning difficulty is also the reason why students' enthusiasm for learning is not high. Job analysis has long been rated as one of the most difficult courses for human resource management teachers in colleges and universities due to its abstract content, few practical cases and lack of rich teaching materials such as recruitment or training (Yun et al., 2018). And Job analysis includes the analysis of enterprise positions, post requirements and post performance assessment, etc. The analysis is based on organizational structure and organizational business process, often involving statistics, economics and other science knowledge, such as the calculation of labor intensity index in this course, the processing of work factor evaluation data and so on. However, the majority of students majoring in human resource management in high school are liberal arts majors with weak science foundation (Shi, 2013). In addition, there are few opportunities for Chinese college students to get in touch with enterprises before entering universities, so it is difficult for them to learn the course of job analysis.

Based on the above analysis, how to design the practical teaching of work analysis based on the characteristics of students and courses, so as to attract students, make them willing to take an active part in it, and make the teaching plan work effectively is the key to the reform of work analysis practical teaching.

\section{Practice Teaching Model of "Job Analysis" Based on Expectation Theory}

In order to enhance the attraction of practical teaching of "Job Analysis" to students, students are encouraged to participate in the practice of "job Analysis" and introduce the theory of expectation. Expectation theory holds that the intensity of motivation depends on the degree to which individuals achieve the desired work performance (organizational goal) of the organization through their efforts, and the organization gives rewards according to the work performance, so as to achieve the degree of consistency and correlation of rewards (individual 
goal) to meet individual needs. Consistent degree or correlation are big, then the effect is big, otherwise it is small (Tang \& Jiang, 2017).

According to the theoretical content of the expectation, it is important to motivate students to study hard. First, study hard can improve learning performance, which depends on students' ability and effort, as well as the depth of understanding of the tasks to be completed, teamwork and so on. Second, the rewards obtained are closely related to learning performance. It depends on the rationality, fairness and scientificity of the learning evaluation system and the group evaluation system. Third, the rewards obtained are highly consistent with the student's personal goals. For ordinary undergraduate students, high-quality employment is the leading demand of students, so the return of practical teaching should be highly consistent with high-quality employment (Figure 1).

\section{Practical Teaching Design of "Job Analysis" Based on Expectation Theory}

\subsection{Design Feasible Teaching Tasks Based on the Nature of Students and Courses}

In the design of job analysis teaching, students should be actively engaged in learning and practicing the teaching tasks that can complete the practical teaching setup, and the completion of these tasks is the student's efforts to complete. Whether students can finish practical teaching tasks or not depends on their ability and effort as well as the depth of understanding of the tasks they need to complete. Due to the difficult content of job analysis and the weak foundation of students' ability, job analysis subdivides the practical tasks of the course into several small tasks to reduce the difficulty in order to ensure that students can complete the teaching tasks. In addition, as the course practice is during the students' class, it is unrealistic to leave the school for a long time to investigate. However, the current scientific and technological environment makes knowledge acquisition channels diverse and fast; make the time and space limitation

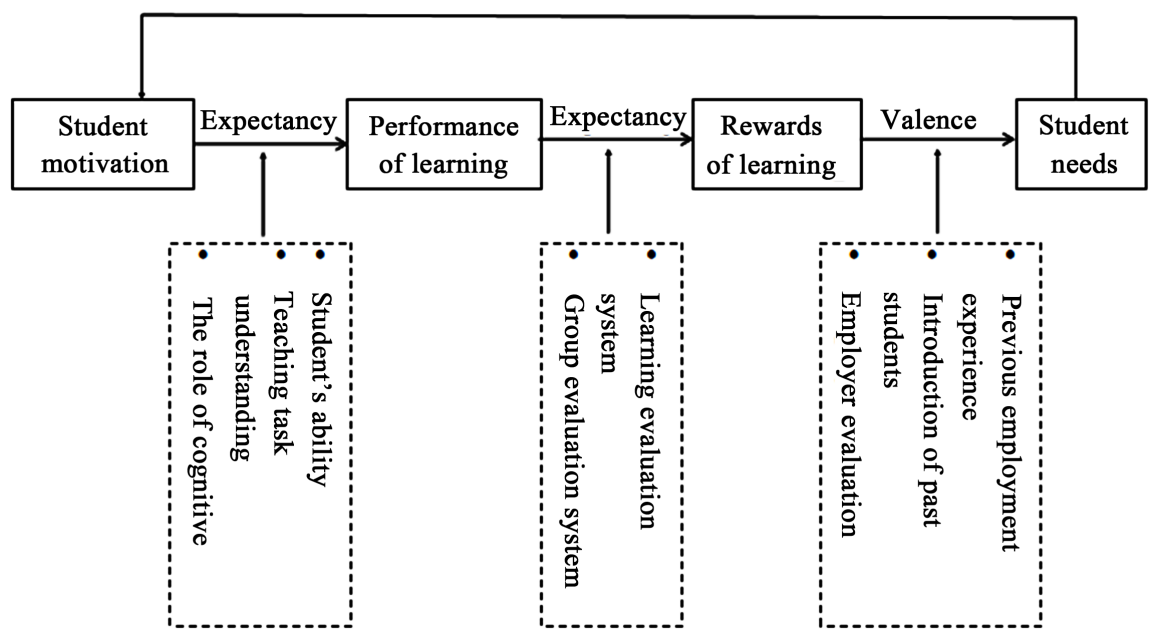

Figure 1. Incentive management model for the course practice of job analysis. 
of knowledge acquisition smaller; increase the amount of knowledge you acquire; let the cost of knowledge acquisition be reduced, etc. (Lu et al., 2018). Therefore, in the practical teaching of job analysis, Internet information and Internet technology should be used as far as possible to complete practical teaching tasks, such as the use of listed companies' annual report information, recruitment information on recruitment websites, and the acquisition of practical teaching materials through social platforms and surveys or interviews with enterprise human resource managers or managers (Cheng, 2018).

\subsection{Teaching Operation Based on Clear Practical Teaching Role}

"Job analysis" practical teaching is completed by groups. Teachers need to guide students to form teaching groups conducive to practical teaching according to their abilities and genders. This teaching group has about 5 - 9 members, which are usually singular and mainly conducive to decision-making. Moreover, it is necessary to communicate with each group to determine the division of labor of the group members, so that each student can clarify his specific practical teaching tasks and understand that he is responsible to the team. At the same time, in the process of practical teaching, teachers also need to guide students to obtain the materials, data processing, emotional comfort, results or failure communication required for practical teaching, so as to ensure the practical teaching in an orderly manner.

\subsection{Design a Reasonable and Scientific Teaching Evaluation System}

The premise of reward acquisition is that the teaching evaluation system is reasonable and scientific. The higher the correlation between performance and reward, the better the incentive effect. The relevance of performance to reward depends on the proportion of rewards related to group performance to individual student rewards, the relevance of student personal development to team performance, and fairness (Bamberger \& Levi, 2009; Zobal, 1999). Therefore, the course practice evaluation system and the group performance evaluation index system should be designed scientifically in the work analysis practice teaching design. In addition, no matter the group or the course practice evaluation index setting, it should be recognized by students, so that students think the evaluation index system setting is fair and reasonable.

\subsection{Practical Teaching Reward System Based on High Quality Employment}

As the external environment of enterprises changes faster and the completion of work analysis and practice tasks should be rewarded accordingly, which may be the score of the course, the knowledge learned, the ability to exercise, others' recognition and so on. The higher the relevance of rewards to individual needs, the better the student's learning efforts. The main need for college students to study is to find high-quality jobs after graduation. High-quality work depends 
on HR-related expertise, professional competence, and industry and corporate knowledge. The higher the student's job analysis practice scores are associated with high quality work, the more motivating students to study hard. However, the correlation between the practical score of job analysis course and the realization of high-quality employment is usually determined by students' experience. Teachers should try their best to guide students to realize that the practice of job analysis course based on expectation theory is conducive to the realization of high-quality employment. For example, the selection of practical materials for courses is from listed Chinese enterprises and their recruitment information, so that students can perceive that practical teaching content is conducive to future employment in the process of collecting information. In the process of practical teaching, teachers further deepen the importance of job analysis to students of human resource management professional knowledge by systematically summarizing practical teaching contents. In addition, teachers should introduce staff from external enterprises to evaluate and analyze the work analysis practice comprehensively in the course teaching evaluation, so that students will think that the higher the course practice score is, the more beneficial it will be for future employment.

\section{The Specific Design of Practical Teaching of "Job Analysis" Based on Expectation Theory}

\subsection{Organize the Course Practice Team}

In accordance with the conditions for the company to set up a team, students recruit and recruit, form a curriculum practice group, elect the team leader within the group, and conduct group division of labor, and form a group performance appraisal mechanism through internal discussion and communication. Group division of labor is conducive to students' cognition of roles and deep understanding of practical teaching tasks. The group performance appraisal mechanism is the consensus agreement reached by the group members on the work of the group and the basis of team cooperation, which restricts the behavior of each group member. For employment consideration, each group chooses different industries, and each group surveys different enterprises. Finally, through group communication and learning, students will learn about the enterprises and job distribution of major industries in China, which not only lays the foundation for learning human resource management, but also enables students to understand the employment industry, enterprises and positions, guide them to focus on the industries or enterprises they are interested in, and prepare for employment.

\subsection{Practical Teaching Task Subdivision}

The practical teaching objective of job analysis is to enable students to apply the job analysis theory they have learned to practice and turn theoretical knowledge into professional ability. To train students' comprehensive abilities of teamwork, 
information collection, learning, problem solving and problem analysis. What's more important is to let students know about China's excellent enterprises, understand the development of the industry, and master the work content of human resource management major in practical teaching. At the same time, let students find suitable enterprises, and focus on tracking the development of these enterprises and industries, to lay a foundation for college graduates to find a job. Therefore, in terms of practical teaching contents, two major practical contents, work cognition and job description writing, are arranged according to the teaching hours. Considering that students seldom use real enterprise information to solve practical problems, it will be very difficult in the process of practical operation. Therefore, each chunk of content should be decomposed into several small practical contents to reduce the difficulty of practice and make students willing to do it and gain something. Generally, the practical task of work cognition is to select enterprises listed at home and abroad, obtain their industry information, organizational structure, system and other information by consulting their open data, and then cooperate with various recruitment websites in China to obtain the current position information.

\subsection{Practice Teaching Operation}

According to each small task of practical teaching, analyze the difficulties that students may encounter and the key points of the course, and assign the requirements of each task to students. After students accept the task, group members discuss the assignment of practical teaching tasks by teachers, define the roles and tasks of each member, discuss in the practical teaching class, analyze the problems existing in the task completion and the completion plan, and communicate with the practical teachers. Use practical teaching or spare time to carry out course practice, and finally complete the task by defining the cycle of division of labor among group members, individual independent learning, group communication and discussion, integration and summary of task results, division of labor of the next task and other links. In the process of group cooperative learning, teachers should timely grasp the progress and quality of tasks completed by each group, and communicate with students in the whole process to help solve the difficult problems encountered by students. Finally, students finish the editing and sorting of the report materials, and determine the report representatives of the module group, so as to make a unified return on practical teaching.

\subsection{Formulate the Evaluation Index System of Practical Teaching}

In the past, practical teaching evaluation was generally conducted by teachers. However, teachers were not clear about the status of students in team learning, and team learning was crucial to the development of practical teaching. Therefore, in order to arouse students' enthusiasm for learning, practice assessment is divided into a group evaluation index system and a practice report evaluation system. The weight of the two parts is $50 \%$, so as to encourage students to attach 
importance to both the practice process and the practice results. The evaluation index system of the group shall be jointly formulated by the members of the group, and the score of each member of the group shall be determined through the mutual evaluation of the group. The performance evaluation index system of a group is generally designed from the perspectives of practical ability, teamwork and practical attitude. Practice report evaluation index system generally includes three aspects: practice content, practice report and practice attitude. Professional teachers, human resource management personnel of research enterprises or students from previous years shall be organized by the teaching teachers to form a comprehensive evaluation group, which will comprehensively evaluate the practice content and report of the group.

\section{Conclusion and Discussions}

The successful implementation of the practical teaching mode of work analysis based on expectation theory requires that the practical teaching instructor is very familiar with the industry, enterprises and positions, and good at subdividing teaching tasks. The design of practical teaching tasks should conform to the students' serious laws, such as the design and decomposition of practical teaching tasks need to consider the difficulty of the task, the content of knowledge points, before and after the correlation degree and other factors; the introduction of various tasks should follow the principles from easy to difficult, from shallow to deep, from point to surface, etc. At the same time, practical teaching instructors are good at communication and timely guide students in their work analysis and practice. Sometimes, they also need to provide encouragement and support to students. Of course, "job analysis" practice teaching also needs students to actively cooperate and implement. There are also some problems in the practical teaching method of the course based on expectation theory. For example, students need to enter the enterprise for research or use WeChat or telephone to conduct research or interview. However, these activities do not bring direct economic benefits to the enterprises under investigation, and will to some extent interfere with the operation of the enterprises. As a result, students will encounter many difficulties in the research process, such as reluctance to accept the research, perfunctory research and so on. In the future, we will further study how to solve these problems and improve the practical teaching of work analysis.

There are some problems in this research. This research is mainly about the assumption of the practical teaching reform of work analysis. Based on this assumption, the preliminary practice of the undergraduate course of Anyang Normal University for 2 years needs to be further tested for its effectiveness. At the same time, the content of the course operation and assessment index design needs to be further refined.

\section{Foundation Item}

2017 teaching reform project of Anyang Normal University "comprehensive reform of human resource management specialty". 


\section{Conflicts of Interest}

The authors declare no conflicts of interest regarding the publication of this paper.

\section{References}

Cheng, F. (2018). The Mechanism and Path of College Students' Accurate Employment: Based on Internet Professional Information. Continue Education Research, 4, 86-89.

Lu, X. L., Jiang, P., Li, N., \& Wang, W. (2018). Reflections on the Reform of Higher Engineering Teaching Methods under the Characteristics of Knowledge Easy Acquisition. Research in Higher Education of Engineering, 2, 147-152.

Shi, Y. (2013). Research on Teaching Strategies of Vocational and Technology-Oriented Professional Courses-A Case Study of "Job Analysis and Post Evaluation" of Human Resource Management Major in Higher Vocational Colleges. China Adult Education, 9, 128-130.

Tang, Q. P., \& Jiang, X. F. (2017). Based on Expectancy Theory: Motivation for Researchers of University Think Tanks-Predicament and Countermeasures. Chinese Public Administration, 1, 63-66

Yun, S. F., Qin, F., Yin, X. Y., \& Xiao, K. Q. (2018). The Application of Task-Driven Teaching Method in the Teaching of Job Analysis. Labor Security World, 20, 80-81. 